\title{
Diabetic Neuropathy
}

\author{
Baqiyyah Conway and Amanda Peltier \\ Additional information is available at the end of the chapter \\ http://dx.doi.org/10.5772/55372
}

\section{Introduction}

Diabetic neuropathy is a common microvascular complication of diabetes mellitus. Diabetic neuropathy is a major risk factor for non-traumatic amputations and is thought to play a role in the pathogenesis of other late complications of diabetes. The two major forms of diabetic neuropathy include generalized neuropathy and autonomic neuropathy. Genreralized neuropathy, affecting motor and sensory peripheral nerves can be subdivided further into polyneuropathies which affect multiple nerves and focal neuropathies. The most common form of generalized neuropathy is distal symmetrical polyneuropathy. Autonomic neuropathy affects peripheral autonomic nerves. These autonomic nerves innervate most organ systems of the body and the skin. Both distal symmetric polyneuropathy and autonomic neuropathy cause substantial morbidity and are associated with a high risk of mortality. The hypothesized mechanisms of diabetic neuropathy include ischemic effects caused by vascular abnormalities, disruption of neuronal metabolism, axonal transport mechanisms and repair capabilities, glycation of peripheral nervous system connective tissue, and glycation of Schwann cells or extracellular matrix. In this chapter, we discuss the diagnostic criteria, pathophysiology, epidemiology, and treatment of peripheral and autonomic neuropathy in type 1 diabetes.

\section{Classification}

Table 1 gives a detailed classification of the neuropathies observed in diabetes. 


\begin{tabular}{|c|c|c|}
\hline Generalized Neuropathy & Focal Neuropathies & Autonomic Neuropathies \\
\hline $\begin{array}{l}\text { Typical: Distal symmetric } \\
\text { polyneuropathy (DSP) }\end{array}$ & Compression: & Cardiovascular autonomic neuropathy \\
\hline Atypical Neuropathy: & Median -carpal tunnel & $\begin{array}{c}\text { Gastrointestinal autonomic } \\
\text { neuropathy }\end{array}$ \\
\hline Insulin Neuritis/Treatment Neuropathy & Ulnar -cubital tunnel & Genitourinary autonomic neuropathy \\
\hline Inflammatory Neuropathy & Fibular-fibular head & $\begin{array}{l}\text { Hypoglycemia unawareness and } \\
\text { associated autonomic failure }\end{array}$ \\
\hline $\begin{array}{c}\text { Chronic inflammatory } \\
\text { demyelinating } \\
\text { polyneuropathy }\end{array}$ & Tibial -tarsal tunnel & Sudomotor autonomic neuropathy \\
\hline Mononeuritis multiplex & $\begin{array}{c}\text { Lateral femoral } \\
\text { cutaneous -inguinal } \\
\text { ligament }\end{array}$ & \\
\hline \multirow[t]{3}{*}{ Diabetic amyotrophy } & Ischemic: & \\
\hline & Thoracic radiculopathies & \\
\hline & $\begin{array}{c}\text { Cranial nerve palsy (III, } \\
\text { VI, VII) }\end{array}$ & \\
\hline
\end{tabular}

Dyck et al. 2011 [1] and Vinik et al 2003 [2]

Table 1. Classification of Diabetic Neuropathy

\section{Diabetic distal symmetric polyneuropathy in type 1 diabetes mellitus}

\subsection{Overview}

Distal Symmetric Polyneuropathy (DSP) is the most common type of neuropathy affecting patients with type 1 diabetes. Polyneuropathy is the greatest risk factor for non-traumatic amputations and confers a higher mortality risk [3,4]. The incidence of DSP increases with duration of diabetes and with degree of hyperglycemia [5]. In type 1 diabetes, typically the incidence of DSP is linked to other microvascular complications of nephropathy and retinopathy [6]. Unlike type 2 diabetes, polyneuropathy is rarely if ever present in the first five years of diagnosis. Metabolic memory in which improved metabolic control, even for a finite period, confers improved outcomes in the future is a phenomenon which was discovered with the Diabetes Complications and Control Treatment Trial, and may be an important factor to consider in the treatment of type 1 diabetic patients [7].

\subsection{Diagnostic criteria}

The case definition of typical DSP or diabetic sensorimotor polyneuropathy from the American Academy of Neurology, American Association of Neuromuscular and Electrodiagnostic 
Medicine, and the American Association of Physical Medicine and Rehabilitation is, "a combination of neuropathic symptoms, multiple signs, and abnormal electrodiagnostic studies" [8]. However, this does not distinguish typical DSP from atypical diabetic neuropathies [1]. A more precise definition for typical DSP proposed by neuromuscular experts at the 2011 Neurodiab Meeting suggested a tiered approach of possible, probable, confirmed and subclinical DSP. Possible DSP includes symptoms or signs of DSP such as decreased distal sensation or depressed ankle reflexes. Probable clinical DSP includes a combination of symptoms and signs of DSP. Confirmed DSP includes symptoms, signs, and abnormal nerve conduction study consistent with DSP (i.e. symmetric). Subclinical DSP would include patients with abnormal nerve conduction studies but no signs or symptoms of neuropathy [1]. Debate is ongoing as to whether abnormal skin biopsy with decreased epidermal nerve fiber density should be considered with nerve conduction study as a confirmatory test.

\subsection{Epidemiology}

The prevalence of DSP in type 1 diabetes mellitus has been postulated to be over $50 \%$ by 25 years of diagnosis $[9,10]$. These data depend on measures used for quantification. Nerve conduction studies are typically more sensitive than monofilament tests and often show decreased conduction velocity in sensory and motor nerves prior to the development of signs or symptoms of sensory loss with monofilament and vibration testing [11]. More tests used, and more sensitive measures will increase prevalence statistics.

Risk factors for DSP incidence and severity in addition to duration of diabetes and age are hyperglycemia, systolic blood pressure, smoking, cholesterol, and height. The Diabetes Control and Complications Trial confirmed hyperglycemia as a significant risk factor for DSP in type 1 diabetes $^{1}$. Interestingly, hyperglycemia alone has not been proven in prospective cohort studies of type 2 diabetes to delay progression in this population [12] which raises the question of whether hyperglycemia is the sole cause of DSP in type 2 diabetes.

Typical progression of DSP in type 1 is very slow, with incremental sensory loss over years and decades. The Diabetes Control and Complications Trial/Epidemiology of Diabetes Interventions and Complications study data show minimal changes in conduction velocity and amplitudes over 5 year periods, which can reassure patients $[13,14]$. Progression typically affects both large, myelinated fibers conveying tactile sensitivity, vibration and joint position sense, and small, unmyelinated fibers conveying temperature and pain sensation. Motor involvement is typically subclinical until later in the disease course. While slowed conduction velocities, particularly in the fibular nerve, are common early signs of DSP, weakness typically occurs later, first affecting the toes and then more proximal muscles.

Inflammatory neuropathies such as mononeuritis multiplex and diabetic amyotrophy affecting the plexus are less common in type 1 diabetes than type 2 [15]. Chronic inflammatory demyelinating polyneuropathy is also more common in type 2 , but has not been shown to

1 *The DCCT was a groundbreaking study of patients with type 1 diabetes in the United States; a large, multicenter study designed to test whether improved glycemic control delayed the onset or progression of diabetic complications. The follow up epidemiologic study, EDIC (Epidemiology of Diabetes Interventions and Complications) continued to follow the same patients enrolled in DCCT, which is still ongoing. 
affect diabetic patients at an increased rate than the general population [16]. Acute painful neuropathy associated with weight loss and abrupt improvement in glycemic control occurs in both type 1 and type 2 patients. This type of neuropathy, formerly known as "insulin neuritis" typically has significant resolution within a year of onset [17].

Sensory symptoms include numbness, or alteration of sensation often described by patients as "wearing multiple socks" or "walking on wood". Neuropathic pain when present can vary between sharp shooting pains, stabbing, or dull and aching. Muscle cramps in feet and legs are common complaints. Hand symptoms can occur when DSP progresses to include the hands in a length dependent process, but more commonly occur because of coexisting compression neuropathies in the hands $[18,19]$.

Coexisting polyneuropathy from other causes also occurs in type 1 diabetes patients and can account for as many as $10 \%$ of DSP cases [9]. The most common include alcoholic neuropathy, B12 deficiency and monoclonal gammopathies. Atypical presentations such as severe distal or proximal weakness, spasticity, faster progression over weeks to months should be signals that a coexistent polyneuropathy may be present and needs evaluation.

\subsection{Pathophysiology}

The polyol pathway was put forth as a possible cause of diabetic neuropathy over 30 years ago when aldose reductase inhibitors were first studied [20]. Since then, the pathophysiology of DSP in type 1 diabetes is still not completely known but several major pathways have been the focus of most studies. 1) increased flux through the polyol pathway; 2) advanced glycation end-products affecting proteins and lipids [21, 22]; 3) increased oxidative stress with impaired mitochondrial function $[23,24], 4)$ protein kinase C inhibition $[25,26]$ and 5) loss of nerve growth factors [27, 28]. Additional mechanisms that have been raised include inflammation, loss of nitric oxide, and hypoxia from microvascular damage [29]. Additional metabolic factors such as hypertriglyceridemia may be more pertinent to type 2 diabetes, although this also occurs in type 1 patients [30,31]. Loss of ATP and AMP production through mitochondrial dysfunction may be a "final common pathway" for these mechanisms to cause neuronal injury [32].

The role of Schwann cells in DSP is still not completely understood. Schwann cells, not neurons produce aldose reductase [33] and are also the source of nerve growth factors such as nerve growth factor (NGF) and brain-derived neurotrophic factor [34, 35]. Schwann cells in culture tend to be more resistant to hyperglycemia than neurons. However, the most recent evidence suggests unmyelinated fibers to be more sensitive to hyperglycemia than myelinated fibers [36]. These may have important implications for biomarkers in treatment studies.

\subsection{Assessment}

The assessment of DSP in type 1 diabetes significantly affects the sensitivity and specificity cited. The simplest assessments used are loss of ankle deep tendon reflexes and detection of pressure from a $10 \mathrm{~g}$ monofilament. Monofilament sensitivity alone ranges from $20 \%$ to $64 \%$ $[37,38]$ and likely improves if multiple sites on the foot are tested (8 sites recommended). Nerve 
conduction studies measuring sensory and motor nerve action potential amplitude, latency, and conduction velocity are typically used for most studies [14]. The most common nerves assessed are sural sensory and fibular motor nerves. These were shown by Dyck et al to be involved earliest [39]. The earliest finding is conduction velocity slowing in the fibular and sural nerves.

Additional measures used include quantitative sensory testing, which can be performed with multiple devices to measure vibration and thermal thresholds [40, 41]. This can be more sensitive than nerve conduction studies but is subjective and not well suited for diagnostic purposes [42]. Quantitative sensory testing is highly reproducible and has been used in several clinical neuropathy studies [43, 44]. Sural nerve biopsy is rarely performed for diagnosis due to its invasiveness (and cannot be repeated) and is usually used to evaluate for other forms of neuropathy such as chronic inflammatory demyelinating polyneuropathy, vasculitis, or inherited neuropathies. Skin biopsy with measurement of intraepidermal nerve fiber density has become more common, especially when combined with chemical axotomy with capsaicin to measure nerve regeneration [36]. Newer noninvasive methods used include confocal microscopy of corneal C fibers [45] or of Meissner corpuscles (mechanoreceptors) in the finger [46, 47].

\subsection{Management}

Management of DSP is largely supportive. The main therapeutic aim is to achieve normoglycemia or HgA1c less than 7 [13]. This can be accomplished with frequent self-monitoring and using insulin pumps for continuous subcutaneous insulin infusion or multiple daily injections. Both the EURODIAB and the Diabetes Control and Complications Trial confirmed therapeutic efficacy in delaying progression of DSP with lower glycemic levels [5, 13]. For treatment of insulin neuritis, management is largely supportive and usually requires relaxing hyperglycemia control somewhat. Inflammatory neuropathies may respond to pulsed IV steroids and intravenous immunoglobulins but class A evidence is still lacking [48, 49]. Diabetic chronic inflammatory demyelinating polyneuropathy is managed similarly to idiopathic chronic inflammatory demyelinating polyneuropathy [50].

Foot care is critical once DSP occurs. Patients should be instructed to inspect their feet every night for new ulcerations, blisters or cuts. Wearing shoes at all times will also decrease the chance of potential injury. Feeling bathwater with hands or more proximal leg is also helpful to avoid burns from insensate feet. As neuropathy occurs, the foot structure will change due to muscle atrophy and due to fractures from insensate feet (Charcot foot). Orthotic inserts may be helpful in preventing further ulceration and stabilizing the feet [51].

Falls are an important complication in DSP and need to be screened for at clinic visits. Evaluation by a physical therapist can be helpful in identifying whether a cane, four-point canes, walkers, wheelchairs should be singular. Home evaluations to improve lighting, minimize obstructions and irregular floors like loose rugs are also important. Adding grab bars in bath areas and minimizing steps can be helpful changes to homes. 


\subsection{Treatment of neuropathic pain}

A significant number of patients with DSP (16-60\%) have symptoms of neuropathic pain [52, 53]. One UK study suggested that painful symptoms were more prevalent in type 2 than type 1 diabetes [53]. Typical pain symptoms are delayed compared to signs of neuropathy in type 1 diabetes [54,55]. The etiology of neuropathic pain in DSP has been thought to be due to abnormalities in C-fiber nerve endings causing aberrant signaling through protein kinase $\mathrm{C}$ [26], increased transient receptor potential vanilloid 1 expression [56], dysregulation of ion channels [57], abnormal nerve growth factor levels [58] and possibly dysregulation of descending pain pathways [59].

Typical pain symptoms described include "burning", "stabbing", "needle-like", "shooting", "electric" etc. Patients often complain of allodynia, e.g. normal sensations become painful such as the touch of bedcovers to the feet, as well as hyperalgesia (painful sensations such as pinprick are unbearably painful). Pain is typically worse at night, and with activities such as walking and standing. Mononeuropathies such as carpal tunnel syndrome can also cause nocturnal paresthesias. Pain symptoms are typically not completely relieved with medications. Pain can be moderate to severe with an average of 5.8/10 on a pain scale [60].

Medications used for neuropathic pain include traditional pain medications such as opioids and tramadol, antiepileptic agents and antidepressants (Table 2) [61]. Typically patients require large doses of opiates for pain relief, and long acting opiates are preferred to provide sustained relief. Sedation, constipation, pharmacologic tolerance and addiction issues are significant barriers and usually prohibit opiates as first line pain treatment in neuropathic pain. Mexiletine, a sodium channel blocker and anti-arrhythmic agent has also been shown to have some analgesic effects [62].

Alpha2-delta inhibitors gabapentin and pregabalin are the most commonly used anti-epileptic medications. These medications act at the dorsal horn of the spinal cord to inhibit voltage gated calcium channels $[63,64]$. The advantage of gabapentin and pregabalin is their renal excretion and lack of interaction with other medications. Main side effects include drowsiness, dizziness, peripheral edema, weight gain, and myoclonic jerks at higher doses. Gabapentin is typically initiated at $300 \mathrm{mg}$ up to three times a day and can be escalated up to $4800 \mathrm{mg}$ in divided doses. Its short half-life requires three to four times a day dosing for optimal pain relief. Pregabalin has a longer half-life and is typically dosed twice a day although some patients benefit from dosing three times a day. Pregabalin is usually started at $75 \mathrm{mg}$ twice a day and titrated up to $300 \mathrm{mg}$ twice a day. Consultation with a nephrologist in dialysis dependent patients is needed due to renal excretion, but does not preclude use in these patients. Typically nephrologists will administer one dose after dialysis. Other anticonvulsants used for neuropathic pain include carbamazepine, oxcarbazepine, valproic acid, lamotrigine, lacosamide, and phenytoin.

Antidepressants acting on norepinephrine such as tricyclic antidepressants and the selective serotonin and norepinephrine reuptake inhibitor duloxetine are also helpful in treating neuropathic pain $[65,66]$. Duloxetine is well tolerated, with few side effects. Caution should be used in patients with renal insufficiency as elevations of systolic blood pressure have been observed. Nausea can occur initially, but can be avoided with initiation at lower doses such 
as $20-30 \mathrm{mg}$ and slow titration up to $60 \mathrm{mg}$. Effectiveness of $120 \mathrm{mg}$ was not statistically different from $60 \mathrm{mg}$ in clinical studies, although some patients report improved benefit at higher doses [65]. Tricyclic antidepressants also have a benefit in patients reporting difficulty initiating sleep due to pain due to their sedating effects. Dosages of 25-100 mg amitriptyline 2 hours before bedtime are typically used. At higher doses and in elderly patients, an ECG should be obtained because of possible effects of tricyclics on QT prolongation and heart block. Side effects include drowsiness, urinary hesitancy, constipation, orthostatic hypotension and erectile dysfunction.

Topical creams are not typically efficacious for painful DSP. Capsaicin cream/patch has shown efficacy [67], but is typically not well tolerated due to the significant initial pain with application. Gloves need to be worn and avoidance of the eyes is necessary. Occasionally $1 \%$ lidocaine patches can be helpful in patients with focal mononeuropathies such as meralgia paresthetica (compression of the lateral femoral cutaneous nerve). Topical compounded creams containing gabapentin, amitriptyline, and ketamine have been used but there are no published reports on efficacy in placebo controlled studies.

\begin{tabular}{ccc}
\hline Anti-Epileptic Medications & Anti-Depressants & Other \\
\hline Gabapentin & $\begin{array}{c}\text { Tricyclic antidepressants (amitriptyline, } \\
\text { nortriptyline, imipramine) }\end{array}$ & Opiates \\
\hline Pregabalin* $^{*}$ & Duloxetine* $^{*}$ & Tramadol \\
\hline Carbamazepine & Mexiletine \\
\hline Lamotrigine & Capsaicin Cream/Patch \\
\hline
\end{tabular}

*FDA approved indication for diabetic neuropathic pain.

Table 2. Pharmacologic Treatments of Neuropathic Pain

\section{Focal neuropathies}

\subsection{Overview and epidemiology}

Other types of neuropathy which can occur include mononeuropathies, typically at compression points such as median mononeuropathy at the wrist, e.g. carpal tunnel syndrome, ulnar neuropathy at the elbow, and peroneal neuropathy at the knee. In the Rochester Diabetes Trial, these occurred at about the same frequency or higher in type 1 vs. type 2 patients [9]. Cranial neuropathies and truncal radiculopathy occur at an increased rate in diabetic patients, but prevalence data for type 1 and type 2 patients is not available. Pain is a common presenting symptom in ischemic ocular motor palsies and thoracic radiculopathies in diabetes [68, 69]. The Veterans Affairs study of type II patients showed decreased prevalence of cranial mononeuropathies with stricter glucose control but data is lacking for type 1 patients [70]. It is not 
uncommon for mononeuropathies to occur prior to the development of DSP or identification of diabetes, particularly in type 2 patients [71,72]. This has not been described in type 1 patients.

Median mononeuropathy at the wrist, e.g. carpal tunnel syndrome is the most common mononeuropathy in diabetes and occurs three to four times as commonly in diabetics compared to healthy controls, and is more common in diabetics with DSP than without [72-74]. Median mononeuropathy has been reported as early as 11 years old [75]. Risk factors for development of carpal tunnel syndrome include obesity and lipid-lowering medications [74].

\subsection{Pathophysiology}

The pathophysiology of mononeuropathies in diabetes is not well understood. They are generally divided into compression-site mononeuropathies, occurring at typical compression points such as the transverse ligament in the wrist (median), cubital tunnel (ulnar nerve), across the knee (fibular nerve), the inguinal ligament (lateral femoral cutaneous nerve/meralgia paresthetica) and tarsal tunnel (tibial nerve). Cranial nerve mononeuropathies and thoracic radiculopathies, diabetic amyotrophies are thought to have an ischemic etiology, either due to microvascular disease (such as cranial nerve involvement) or inflammation (diabetic amyotrophy). Some patients (described in type 2 diabetes) have a rapid development of multiple mononeuropathies which is indistinguishable from a vasculitic mononeuritis multiplex in presentation and can be associated with inflammation on biopsy [76].

The greater prevalence of compression mononeuropathies in diabetes (20-30\% of Type 1 and 2 patients) $[9,77]$ has been observed for decades, but the pathophysiology is not well known. Experimental compression neuropathies trigger Schwann cell proliferation, apoptosis causing local demyelination then remyelination. This occurs prior to the development of axonal degeneration [78]. The median nerve when visualized with ultrasonography is larger in patients with compression compared to healthy controls which may be due to remyelination [79]. It has been presumed that hyperglycemia injured nerves are more vulnerable to compression than normal nerves. Another possibility is lack of symptoms in the diabetic may make compression mononeuropathies worse because of delayed recognition [77]. Other possible etiologies include greater edema within the nerve and diabetic cheiroarthropathy (thickening/ fibrosis of the flexor synovium from excessive connective tissue) [80, 81].

\subsection{Assessment}

Identification of mononeuropathies may be based on signs and symptoms localizable to a specific nerve in a diabetic patient (e.g. ptosis, diploplia in a Cranial nerve III/oculomotor nerve palsy). This is typically the case for cranial nerve palsies, optic neuropathies, thoracic radiculopathies, or lateral femoral cutaneous nerve palsy where the distribution of deficit is pathognemonic. If the symptoms and signs are specific to one cranial nerve in a previously diagnosed diabetic patient, imaging with magnetic resonance imaging, CT or other modality is typically not needed to confirm the diagnosis. Especially in cranial nerve III palsies, there is controversy whether imaging should occur in a diabetic patient with a classical papillary-sparing presentation $[82,83]$. 
Mononeuropathies may be identified on testing with nerve conduction studies. This is more common in carpal tunnel syndrome, ulnar mononeuropathy, and fibular mononeuropathy which are often asymptomatic. Nerve conduction studies in compression mononeuropathies distally typically demonstrate slowing of conduction velocity across the compressed segment (ulnar, fibular, tibial nerve) or increased distal latency compared to nearby nerves (median nerve). Multiple nerves are often compared, or side to side comparisons are made to exclude underlying DSP.

For carpal tunnel syndrome, nerve ultrasound has become a more common procedure, demonstrating enlarged median nerve cross sectional area in the wrist in affected individuals compared to controls [84]. Thus far, no differentiation between ultrasound appearance of diabetic vs. non-diabetic nerves have been found [85]. Another study suggested a larger cross-sectional area of the tibial nerve at the tarsal tunnel in diabetic patients [86]. Further studies are still needed on the utility of this measure for diabetic patients. Magnetic resonance imaging is also used for assessment of carpal tunnel syndrome, but data in diabetes vs. control patients is lacking and cost is significantly higher than nerve conduction studies or ultrasound [87].

\subsection{Treatment}

Treatment of compression induced mononeuropathies is aimed at relieving the site of trauma. Bracing, avoiding extenuating activity, and changing postures are initial non-surgical approaches. Data for surgical approach to compressive neuropathy is better known in median mononeuropathies at the wrist (carpal tunnel syndrome) because of larger reported cohort studies. However, data are conflicting in regards to outcome of carpal tunnel syndrome surgical release with some studies showing poorer outcomes and some not significantly different from non-diabetic patients $[88,89]$. This may occur due to differences in patient selection. Results of surgical release of the ulnar nerve at the cubital tunnel, the second most common mononeuropathy $(2.1 \%)$ are worse compared to carpal tunnel syndrome [81, 90]. It is not clear whether this is due to underlying diabetic polyneuropathy or due to patient selection bias (misdiagnosis).

Treatment of ischemic induced mononeuropathies is typically supportive. Pain management is often needed for thoracic radiculopathies, meralgia paresthetica (lateral femoral cutaneous nerve palsy). Prisms or patching can be used for diploplia in ocular motor cranial nerve palsies (cranial nerve 3, 4, and 6). Taping of the eyelid and lubrication may be needed in facial nerve palsies to prevent corneal abrasion. Little data are available for prognosis. Many patients improve over 3-6 months, but some may have permanent muscle weakness or ptosis [91, 92]. Treatment with intravenous alpha-lipoic acid has also been reported as improving outcomes but was not placebo controlled [93]. Otherwise, treatment for mononeuropathies in diabetes is not significantly different than in non-diabetics. 


\section{Diabetic autonomic neuropathy}

\subsection{Overview}

Autonomic neuropathy is a form of peripheral neuropathy affecting the nerves of the autonomic nervous system. Autonomic neuropathy most commonly affects organs of the cardiovascular, gastrointestinal, urinary, and reproductive systems, although any system of the body may be affected. Its etiology is poorly understood, but as with other forms of peripheral neuropathy long exposure to hyperglycemia, advanced glycation end products, vascular hypoxia [94], and activation of the polyol pathway are thought to play major roles. Typical signs and symptoms depend on the organ affected, but include resting sinus tachycardia without sinus arrhythmia, orthostatic hypotension, delayed gastric emptying, diabetic diarrhea, constipation, erectile dysfunction, bladder dysfunction, hypoglycemia unawareness, distal hyperhidrosis or anhidrosis, facial sweating, and gustatory sweating. Cardiovascular autonomic neuropathy is life threatening and carries a high risk of mortality $[2,95,96]$.

\subsection{Epidemiology}

The prevalence of autonomic neuropathy in type 1 diabetes populations varies widely depending on duration of diabetes and method of assessment, with prevalences ranging from $2.6 \%$ in individuals with short duration of diabetes [97] to $90 \%$ in pancreatic transplant candidates [98]. Defining autonomic neuropathy based on an abnormal heart rate response to deep breathing and the presence of at least two autonomic neuropathy symptoms, the prevalence ranged from $3.7 \%$ to $11.3 \%$, with a decreasing trend with higher BMI, in the Pittsburgh Epidemiology of Diabetes Complications (EDC) when the mean duration of diabetes was approximately 20 years [96]. In a subgroup of this same cohort twenty years later, when mean diabetes duration was 40 years, the prevalence of autonomic neuropathy based on an abnormal response to deep breathing was 61\% [99]. In the entire EDC cohort, the incidence of autonomic neuropathy based on an abnormal heart rate response to deep breathing and the presence of at least two autonomic neuropathy symptoms was 0.78 per 100 person years of duration of diabetes, with a lower incidence for a given duration of diabetes in more recently diabetes diagnosed cohorts in the Pittsburgh Epidemiology of Diabetes Complications study [100]. In the Diabetes Control and Complications Trial/ Epidemiology of Diabetes Interventions and Complications study population, which because of inclusion criteria was a healthier cohort at study baseline than the EDC population, the prevalence of autonomic neuropathy at the follow-up years 13/14 of Epidemiology of Diabetes Interventions and Complications study, representing approximately 27 years of duration of type 1 diabetes, was $29 \%$ and $35 \%$ in the former intensively treated and conventionally treated Diabetes Control and Complications Trial participants [10]. The presence of diabetic autonomic neuropathy is associated with poor prognosis. In the EDC study, mortality during 20 years of follow-up was increased 2.43-fold after controlling for age, sex, BMI, and other late complications [96]. 


\subsection{Pathophysiology}

Diabetic autonomic neuropathy is a neuropathic disorder of the peripheral nervous system in individuals with diabetes or prediabetes. The pathogenesis of diabetic autonomic neuropathy is poorly understood, but long exposure to hyperglycemia [94, 101], advanced glycation end products $[2,94,101]$, vascular insufficiency $[2,94]$, and activation of the polyol pathway $[2,94$, 101] have been long thought to play major roles. The nerves of the autonomic nervous system innervate every organ of the body and as such any organ system can be affected by diabetic autonomic neuropathy. Disorders resulting from damage to autonomic nerve fibers are typically classified into the following syndromes: cardiovascular autonomic neuropathy (CAN), gastrointestinal, genitourinary, hypoglycemia unawareness, and sudomotor.

\subsubsection{Pathogenesis}

Long exposure to hyperglycemia is one of the strongest hypotheses on the etiology of diabetic peripheral neuropathy. In individuals with type 1 diabetes, results from the Diabetes Control and Complications Trial showed significantly lower declines in the R-R interval over time in those in the intensive therapy arm of the trial [97]. Whether this was due to lower levels of hyperglycemia was not specified. There was a low incidence of CAN in both treatment arms ( $4 \%$ in the intensive group and $9 \%$ in the conventional group), with a $45 \%$ lower incidence in the treatment arm [10]. Follow-up of the entire cohort thirteen to fourteen years after the closeout of the trial revealed a marked increase in the prevalence of CAN in the entire cohort, which was significantly greater in the former conventional therapy group. Differences in $\mathrm{HbA} 1 \mathrm{c}$ accounted for the majority of the group differences in the incidence of CAN [102]. The beneficial effect of former intensive therapy on the incidence of neuropathy appeared to be greater for CAN than for distal symmetrical polyneuropathy, suggesting that the detrimental effect of hyperglycemia may be greater on small nerve fibers than large nerve fibers [10]. Mechanisms by which hyperglycemia may cause nerve damage include activation of the polyol pathway and accumulation of advanced glycation end products [2, 94, 101].

\subsubsection{Cardiovascular Autonomic Neuropathy (CAN)}

Cardiovascular autonomic neuropathy results from damage to the nerves that innervate the heart and coronary blood vessels. Because of its clinical importance, it has been the most studied of all of the diabetic autonomic neuropathy syndromes. It is the most life threatening of all of the diabetic autonomic neuropathy syndromes and carries a high risk of mortality. Signs/symptoms of CAN include orthostatic hypotension, sinus tachycardia, exercise intolerance, silent myocardial infarction, and sudden death.

Autonomic nervous system innervation of the heart largely regulates heart rate variability. In diabetes, cardiac autonomic nervous system dysfunction generally progresses from the apex to the base of the heart [103]. Diabetic autonomic neuropathy appears to affect the long nerve fibers first [2]. In CAN, autonomic dysfunction is usually observed first as a decrease in parasympathetic activity, reflecting damage to the vagal nerve, the longest of the autonomic nerve fibers, and a compensatory increase in sympathetic autonomic nervous system activity 
[103]. Sympathetic activity increases heart rate while parasympathetic activity decreases heart rate. The decline in parasympathetic activity is reflected in the decline in variation in heart rate with inspiration and expiration, where there is less of a decline in heart rate with expiration. A decline in heart rate variability is one of the earliest manifestations of CAN [103]. This compensatory increase in heart rate with parasympathetic denervation also manifests in an increased resting heart rate, and rates may reach greater than 100 beats per minute [103], resting sinus tachycardia.

Autonomic innervation of the heart also regulates blood pressure. The apparent early vagal denervation in CAN results in increased sympathetic nervous system activity, partially due to the counter-regulatory activity of the parasympathetic neurons, increasing blood pressure. During sleep, this is reflected in the "non-dipping" pattern of blood pressure often observed in individuals with type 1 diabetes [104, 105]. This lack of nocturnal bradycardia is associated with prolongation of the heart rate corrected Q-T interval in adolescents with type 1 diabetes [106], although Stella et al [105] observed no cross-sectional association between "nondipping" and CAN in adults with type 1 diabetes. Later cardiac sympathetic denervation results in loss in the normal heart rate and blood pressure responses to exercise. The normal increase in heart rate and blood pressure and subsequent increased cardiac output is impaired, reducing exercise tolerance $[2,103]$. Sympathetic cardiac denervation also manifests as orthostatic hypotension, a prolonged drop in blood pressure upon standing due to reduced baroreceptor stimulated sympathetic increase in heart rate and vasoconstriction of splanchnic vascular beds. Orthostatic hypotension may often be asymptomatic, but can result in dizziness, syncope, falls and fractures.

CAN is associated with silent myocardial ischemia and infarction [2, 107], and carries a high risk of mortality [95, 96]. The association of diabetic CAN with silent myocardial infarction is likely due to the higher frequency of silent myocardial ischemia in individuals with diabetic CAN [2]. Damage to the myocardial sensory afferent fibers may reduce the sensation of ischemic pain [2]. A meta-analysis of twelve studies of individuals with diabetes showed a 2-fold higher risk of silent ischemia in those with CAN [2]. In a population of middle-age and elderly individuals with type 1 diabetes, poorer cardiac autonomic function predicted future coronary heart disease events [108]. Perhaps due to its association with silent myocardial ischemia, cardiovascular disease, resting tachycardia, and exercise intolerance, CAN greatly increases the risk of sudden death [109-111]. We have shown in individuals with long-standing type 1 diabetes that CAN as diagnosed based on heart rate variability and in the presence of at least one other symptom of autonomic neuropathy was a significant predictor of mortality, independently of distal symmetrical polyneuropathy and other late complications of diabetes [96].

\subsubsection{Gastrointestinal autonomic neuropathy}

Diabetic autonomic neuropathy affecting the gastrointestinal system may result in gastroparesis, esophageal dysfunction, diarrhea, fecal incontinence, or constipation. Gastroparesis, or delayed gastric emptying, is common in type 1 diabetes, with prevalence rates from approximately 30 to $50 \%[4,112-114]$ and appears to be more prevalent in type 1 than in type 2 diabetes 
[115]. Symptoms of gastroparesis include nausea, vomiting, anorexia, bloating, early satiety, and wide swings in blood sugar [112]. hyperglycemia delays gastric emptying [116] while hypoglycemia accelerates it [117]. Esophageal dysfunction is thought to result from a combination of impairment of vagal nerve and enteric nervous system innervation of esophageal smooth muscle cells regulating peristalsis [117]. Symptoms of esophageal dysfunction include difficulty swallowing (dysphagia) and heartburn. Peristalsis dysmotility of the lower gastrointestinal track can result in diarrhea or constipation, both very commonly observed in type 1 diabetes. The diarrhea may be due to bacteria overgrowth resulting from bowel stasis, very rapid peristalsis, or both. Very slow peristalsis activity may result in constipation. Fecal incontinence results from poor anal sphincter tone and impaired rectal sensation [2].

\subsubsection{Genitourinary autonomic neuropathy}

Autonomic nerve dysfunction or damage affecting the genitourinary system may manifest as erectile and/or ejaculation dysfunction or failure in males, dyspareunia in females, and bladder dysfunction, in both genders. Autonomic neuropathy affecting the reproductive organs manifests as erectile and ejaculation failure in males and reduced sexual arousal, reduced vaginal lubrication and painful intercourse in females. Autonomic neuropathy affecting the urinary tract may result in decreased frequency of urination and increased urinary tract infections, increased post void residual volume, dribbling, and urinary incontinence [118, 119].

Erectile dysfunction in diabetes may be due to one or any combination of the following: neuropathy, atherosclerosis, changes in corporal erectile tissue including deposition of AGEs, anti-hyperglycemic medications, and psychological factors, although neuropathy appears to be the predominate cause [119]. The corpus cavernosum is innervated by both sympathetic and parasympathetic nerve fibers and sensory and somatic nerve fibers [120, 121]. The neurogenic basis of erectile dysfunction is a decrease in smooth muscle relaxation of the corpus cavernosum [119, 122], inadequate nitric oxide synthase activity [119, 122], impaired sensation of the glans penis [119, 120], and abnormal motor function of erectile tissue [119].

Little is known about the pathogenesis of sexual dysfunction in women. It is characterized by reduced sexual arousal, atrophic vaginitis and subsequent painful intercourse. It is poorly related to glycemic control, age, duration of diabetes, or diabetes complications [123], but appears to be related to depression and to improve with estrogen creams [118]. In a substudy of the Diabetes Control and Complications Trial/ Epidemiology of Diabetes Interventions and Complications cohort examining female sexual dysfunction in 424 women with type 1 diabetes and a mean age of 42.8 years, the prevalence of female sexual dysfunction was 35\% [124].

Bladder dysfunction is one of the most common complications of diabetes, affecting a large proportion of the type 1 diabetic population [117] and occurring early in the disease process. The diabetic neurogenic bladder is caused by degeneration of both afferent myelinated and efferent non-myelinated nerve fibers to the bladder. Afferent nerve fiber degeneration results in reduced sensation of a full bladder [125]. Efferent nerve fiber degeneration results in reduced frequency of micturition, incomplete emptying of the bladder, i.e. increased post-void residual volume, and eventually urinary incontinence [125]. The neurogenic bladder is associated with recurrent urinary tract infections [125] and may lead to renal failure/disease. 


\subsubsection{Hypoglycemia unawareness and associated autonomic failure}

Autonomic neuropathy is associated with more severe hypoglycemic events [126, 127] and the loss of symptoms prompting awareness of hypoglycemia [128, 129]. However, the jury is still out on whether autonomic neuropathy actually causes a loss of counter-regulatory responses to hypoglycemia [130]. Hypoglycemia associated autonomic failure (HAAF) can occur in the absence of autonomic neuropathy [126, 131, 132]. Conversely, diabetic autonomic neuropathy is observed in the absence of hypoglycemia symptom loss [131, 133]. Additionally, reversal of hypoglycemia symptom awareness is observed after strict avoidance of hypoglycemia for a relative short period of times, i.e. several weeks to months [134-136]. This would all appear to suggest that autonomic neuropathy is not a causative factor in hypoglycemia unawareness, i.e. the loss of the counter-regulatory responses to hypoglycemia. However, in the presence of autonomic neuropathy and in combination with HAAF a greater reduction in counterregulatory response hypoglycemia is observed than in hypoglycemia unawareness without autonomic neuropathy [130]. Furthermore, the recovery of hypoglycemia awareness symptoms with strict avoidance of hypoglycemia is not as complete in those with autonomic neuropathy [128]. Even with the recovery of awareness symptoms, the epinephrine response to hypoglycemia is only partially recovered and even less so in those with autonomic neuropathy [130]. In aggregate, this suggests that autonomic neuropathy is not the predominate cause of hypoglycemia unawareness but does enhance its severity and may play a partial etiologic role.

\subsubsection{Sudomotor autonomic neuropathy}

Abnormalities in thermoregulation are common in type 1 diabetes $[137,138]$. The sweat glands are innervated by sudomotor postganglionic unmyelinated sympathetic c-fibers. Autonomic neuropathy affecting sudomotor nerve function results in both anhidrosis and hyperhidrosis. Sudomotor dysfunction manifests symptomatically as dry scaly skin of the limbs and appendages, heat intolerance, and gustatory sweating. With increasing duration of diabetes, anhidrosis becomes more severe, progressing in a distal to proximal direction [118]. Gustatory sweating, in which there is excessive sweating in the face and trunk in response to eating is thought to result from imperfect reinnervation of postganglionic sudomotor C-fibers following denervation [118].

\subsection{Assessment}

Assessment of cardiovascular autonomic nervous system function can be done by measuring heart rate variability, the heart rate response in postural change from lying or sitting to standing, the blood pressure change from lying or sitting to standing, and the diastolic blood pressure response to a sustained hand grip. Heart rate variability can be assessed my measuring the heart rate response to paced deep breathing, the Valsava maneuver, and spectral analysis. The heart rate response to deep breathing and the heart rate response to a change in posture to the standing position predominately reflect parasympathetic function [2]. The heart rate response to the Valsalva maneuver reflects both parasympathetic and sympathetic function fairly equally [2]. The change in blood pressure from a lying or sitting position to a 
standing position and the blood pressure response to a sustained hand grip reflects sympathetic nervous system function [2].

Assessment of autonomic neuropathy affecting the gastrointestinal track can be done by endoscopy and scintographic measurement of esophageal bolus transit time for esophageal dysfunction; scintography, isotope breath tests, and ultrasonography for gastroparesis; hydrogen breath test for diabetic diarrhea; barium enema for constipation; and anorectal manometry, endoanal ultrasonography, colon transit tests, digital examination of the rectum, protoscopy and sigmoidoscopy for fecal incontinence [2, 139].

Erectile dysfunction can be assessed by taking a case history, such as with the International Index of Erectile Dysfunction, by physical examination including examining of external genitalia, blood tests including measurement of testosterone levels, measurement of nocturnal penile tumescence, and Doppler studies [2, 117, 140]. The Female Sexual Function Index has been used to evaluate sexual dysfunction in women with type 1 diabetes [124]. Vaginal plethysmography has also been used to directly assess vaginal lubrication in women with diabetes [141].

Post void residual volume can be assessed by transurethral catherization or non-invasively via ultrasound [142]. Bladder sensation and upper urinary tract dilation can be assessed with cystometry and voiding cystometrogram. Uroflometry can be used to assess urinary flow rate and sphincter function. A urine culture should also be done to assess bacteria cystitis. In women, a urogynecological examination should be done in order to exclude pelvic prolapse.

Assessment of sudomotor function can be done with the Quantitative Sudomotor Axon Reflex Test (QSART), thermoregulatory sweat test, or the sympathetic skin response. The thermoregulatory sweat test can be used to assess the pattern and distribution of anhydrosis [143]. The QSART is used to assess postganglionic sudomotor nerve function [119, 143]. The sympathetic skin response assesses postganglionic sudomotor sympathetic nerve fibers [144].

\subsection{Management}

Treatment and management of diabetic autonomic neuropathy includes tight glycemic control [4]; however, the primary focus is on alleviation of symptoms [4, 101]. Management of orthostatic hypotension consists of educating the patient in strategies to avoid or address reversible causes of hypotension, increased fluid and salt consumption supplemented with mineralocorticoid therapy, pharmacotherapy with sympathomimetic agents, and wearing clothing such as compression stockings that increase venous return [2, 101, 118]. Antioxidants and cardioselective beta-blockers may be beneficial in cardiac autonomic neuropathy [2].

For patients with esophageal dysmotility, proton pump therapy is conventionally used [119]. Fluid consumption immediately after consumption of medications should be advised in order to avoid pill-induced esophagitis in these patients [119]. Diets low in fat and soluble fiber may be beneficial in patients with gastroparesis [2, 119], although pharmacotherapy with prokinetic agents is the mainstay of therapy [119]. Insulin pump therapy may 
also help to improve symptoms in type 1 diabetic patients with gastroparesis [119]. Antibiotic therapy is beneficial in the treatment of diarrhea [2, 119].

Treatment of bladder dysfunction may be behavioral, pharmacological, or surgical. Behavioral management includes pelvic floor exercises to strengthen the muscles of the pelvic floor that support the bladder and urethretha. It also includes a program of scheduled fluid intake and micturition, manual procedures such as the Crede's maneuver, pelvic tapping, the Valsava maneuver, and clean intermittent self-catheterization. Pharmacotherapy includes the use of antimuscarinic agents, cholinergic agents, and tricyclic antidepressants. In cases refractory to non-pharmacological and pharmacological treatment, surgical procedures such as vesicle neck resection, selective pudendal nerve block, unilateral pudendal neurectomy, and sacral neuromodulation may be beneficial $[2,119,142,145]$.

Treatment and management of erectile dysfunction should include psychological counseling; however, pharmacotherapy with the PDE5 inhibitors (sildenafil, vardenafil, tadalafil) is the mainstay of therapy. Intracavernous or intraurethral injections with vasoactive medication, vacuum constriction devices, and penile prosthesis implantation are also options [2, 119]. Vaginal estrogen creams in has been shown to be beneficial in diabetic women with female sexual dysfunction [118].

\section{Conclusion}

Peripheral and autonomic neuropathy is a common complication of type 1 diabetes with significant morbidity and mortality. Fortunately, aggressive hyperglycemia control can delay the onset and minimize the severity of neuropathy in this population. The pathophysiology of neuropathy is complex and likely involves multiple mechanisms, which may be the reason for lack of efficacious treatments beyond glucose control. Early recognition of peripheral and autonomic neuropathy is also important to decrease amputation risk and mortality.

\section{Author details}

Baqiyyah Conway ${ }^{1^{*}}$ and Amanda Peltier ${ }^{2}$

*Address all correspondence to: baqiyyah@yahoo.com

1 Department of Epidemiology, School of Public Health, West Virginia University, Morgantown, West Virginia, USA

2 Division of Neurology, Department of Medicine, Vanderbilt University, Nashville, TN, USA 


\section{References}

[1] Dyck PJ, Albers JW, Anderson H, Arezzo JC, Biessels GJ, Bril V, et al. Diabetic Polyneuropathies: Update on Research Definition, Diagnostic Criteria and Estimation of Severity. Diabetes Metab Res Rev. 2011. Epub Jun 21, 2011.

[2] Vinik AI, Maser RE, Mitchell BD, Freeman R. Diabetic Autonomic Neuropathy. Diabetes Care. 2003;26:1553-79.

[3] Coppini DV, Bowtell PA, Weng C, Young PJ, Sonksen PH. Showing neuropathy is related to increased mortality in diabetic patients-a survival analysis using an accelerated failure time model. J Clin Epidemiol. 2000;53(5):519-23.

[4] Boulton AJ, Vinik AI, Arezzo JC, Bril V, Feldman EL, Freeman R, et al. Diabetic Neuropathies: a statement by the American Diabetes Association. Diabetes Care. 2005;28(4):956-62.

[5] Tesfaye S, Stevens LK, Stephenson JM, Fuller JH, Plater M, Ionescu-Tirgoviste C, et al. Prevalence of diabetic peripheral neuropathy and its relation to glycaemic control and potential risk factors: the EURODIAB IDDM Complications Study. Diabetologia. 1996;39(11):1377-84.

[6] Fagerberg SE. Studies on the pathogenesis of diabetic neuropathy. III. Diabetic neuropathy in relation to diabetic vessel complications. Acta Med Scand. 1957;157(5): 401-6.

[7] Albers JW, Herman WH, Pop-Busui R, Martin CL, Cleary P, Waberski B. Subclinical neuropathy among Diabetes Control and Complications Trial participants without diagnosable neuropathy at trial completion: possible predictors of incident neuropathy. Diabetes Care. 2007;30(10):2613-8.

[8] England JD, Gronseth GS, Franklin G, Miller RG, Asbury AK, Carter GT, et al. Distal symmetric polyneuropathy: a definition for clinical research: report of the American Academy if Neurology, the Amerian Association of Electrodiagnostic Medicine, and the American Academy of Physical Medicine and Rehabilitation. Neurology. 2005;65(2):199-207.

[9] Dyck PJ, Kratz KM, Karnes JL, Litchy WJ, Klein R, Pach JM, et al. The prevalence by staged severity of various types of diabetic neuropathy, retinopathu, and nephropathy in a population-based cohort: the Rochester Diabetic Neuropathy Study. Neurology. 1993;43(4):817-24.

[10] Pop-Busui R, Herman WH, Feldman EL, Low PA, Martin CL, Cleary PA, et al. DCCT and EDIC Studies in Type 1 Diabetes: Lessons for Diabetic Neuropthy Regarding Metabolic Memory and Natural History. Curr Diab Rep. 2010;10:276-82. 
[11] Dyck PJ, O'Brien PC, Litchy WJ, Harper CM, Klein CJ, Dyck PJB. Monotonocity of nerve tests in diabetes: subclinical nerve dysfunction precedes diagnosis of polyneuropathy. Diabetes Care. 2005;28(9):2192-200.

[12] Intensive blood-glucose control with sulphonylureas or insulin compared with conventional treatment and risk of complications in patients with type 2 diabetes (UKPDS 33). Lancet. 1998;352:837-53.

[13] The effect of intensive treatment of diabetes on the development and progression of long-term complications in insulin-dependent diabetes mellitus. The Diabetes Control and Complications Trial Research Group. N Engl J Med. 1993;329(14):977-86.

[14] Albers JW, Herman WH, Pop-Busui R, Feldman EL, Martin CL, Cleary PA, et al. Effect of prior intensive treatment during the Diabetes Control and Complications Trial (DCCT) on peripheral neuropathy in Type 1 diabetes during the Epidemiology of Diabetes Interventions and Complications (EDIC) Study. Diabetes Care. 2010;33(5): 1090-6.

[15] Dyck PJ, Windebank AJ. Diabetic and nondiabetic lubosacral radiculoplexus neuropathies: new insights into pathophysiology and treatment. Muscle Nerve. 2002;25(4): 477-91.

[16] Laughlin RS, Dyck PJ, Melton LJ 3rd, Leibson C, Ransom J, Dyck PJB. Incidence and prevalence of CIDP and the association of diabetes mellitus. Neurology. 2009;73(1): 39-45.

[17] Vinik A. Approach to the Management of the Patient with Neuropathic Pain. J Clin Endocrinol Metab. 2010;95(11):4802-11.

[18] Stamboulis E, Voumvourakis K, Andrilopoulou A, Koutsis G, Tentolouris N, Kodoounis $\mathrm{A}$, et al. Association between asymptomatic median mononeuropathy and diabetic polyneuropathy severity in patients with diabetes mellitus. J Neurol Sci. 2009;278(1-2):41-3.

[19] Singh R, Gamble G, Cundy T. Lifetime risk of symptomatic carpal tunnel syndrome in Type 1 diabetes. Diabet Med. 2005;22(5):625-30.

[20] Gabbay KH, Spack N, Loo S, Hirsch HJ, Ackil AA. Aldose reductase inhibition: studies with alrestatin. Metabolism. 1979;28(4 S1):471-6.

[21] Sugimoto K, Nishizawa Y, Horiuchi S, Yagihashi S. Localization in human diabetic peripheral nerve of NE-carboxymethyllysine-protein adducts, an advanced glycation endproduct. Diabetologia. 1997;40:1380-7.

[22] Jack M, Wright D. Role of advanced glycation endproducts and glyoxidase I in diabetic peripheral sensory neuropathy. Transl Res. 2012;159(5):355-65. 
[23] Cameron NE, Cotter MA, Maxfield EK. Anti-oxidant treatment prevents the development of peripheral nerve dysfunction in streptozotocin-diabetic rats. Diabetologia. 1993;36(4):299-304.

[24] Lupachyk S, Shevalye H, Maksimchyk Y, Drel VR, Obrosova IG. PARP inhibition alleviates diabetes-induced systemic oxidative steress and neural tissue 4-hydoxynonenal adduct accumulation: correlation with peripheral nerve function. Free Radic Biol Med. 2011;50(10):1400-9.

[25] Cameron NE, Cotter MA, Jack AM, Basso MD, Hohman TC. Protein kinase C effects on nerve function, perfusion, $\mathrm{NA}(+), \mathrm{K}(+)$-ATPase activity and glutathione content in diabetic rats. Diabetologia. 1999;42(9):1120-30.

[26] Ahlgren SC, Levine JD. Protein kinase C inhibitors decrease hyperalgesia and C-fiber hyperexcitability in the streptozotocin-diabetic rat. J Neurophysiol. 1994;72(2):684-92.

[27] Apfel SC, Arezzo JC, Brownlee M, Federoff H, Kessler JA. Nerve growth factor administration protects against experimental diabetic sensory neuropathy. Brain Res. 1994;634(1):7-12.

[28] Feradji V, Sotelo J. Low serum levels of nerve growth factor in diabetic neuropathy. Acta Neurol Scand. 1990;81(5):402-6.

[29] Obrosova I. Diabetes and the peripheral nerve. Biochemica et Biophysica Acta. 2009;1792:931-40.

[30] Callaghan BC, Hur J, Feldman EL. Diabetic neuropathy: one disease or two? Curr Opin Neurol. 2012;25(5):536-41.

[31] Wiggin TD, Sullivan KA, Pop-Busui R, Amato A, Sima AA, Feldman EL. Elevated triglycerides correlate with progression of diabetic neuropathy. Diabetes. 2009;7(1634-1640).

[32] Vincent AM, Edwards JL, McLEan LL, Hong Y, Cerri F, Lopez I, et al. Mitochondrial biogenesis and fission in axons in cell culture and animal models of diabetic neuropathy. Acta Neuropathol. 2010;120(4):477-89.

[33] Ludvigson MA, Sorenson RL. Immunohistochemical localization of aldose reductase. I. Enzyme purification and antibody preparation--localization in peripheral nerve, artery, and testis. Diabetes. 1980;29(6):438-49.

[34] Bradley JL, Thomas PK, King RH, Muddle JR, Ward JD, Tesfaye S, et al. Myelinated nerve fibre regeneration in diabetic sensory polyneuropathy: correlation with type of diabetes. Acta Neuropathol. 1995;90(4):403-10.

[35] Tosaki T, Kamiya H, Yasuda Y, Naruse K, Kato K, Kozakae M, et al. Reduced NGF secretion by Schwann cells under the high glucose condition decreases neurite outgrowth of DRG neurons. Exp Neurol. 2008;213(3):381-7. 
[36] Polydefkis M, Hauer P, Sheth S, Sirdofsky M, Griffin JW, McArthur JC. The time course of epidermal nerve fibre regeneration: studies in normal controls and in people with diabetes, with and without neuropathy. Brain. 2004;127(Pt 7):1606-15.

[37] Miranda-Palma B, Sosenko JM, Bowker JH, Mizel MS, Boulton AJM. A comparison of the monofilament with other testing modalities for foot ulcer susceptibility. Diabetes Res Clin Pract. 2005;70(1):8-12.

[38] Wang Y, Goodrich JM, Werner R, Gillespie B, Basu N, Franzblau A. Agreement between clinical screening procedures for neuropathy in the feet. Muscle Nerve. 2012;45(5):653-8.

[39] Dyck PJ, Davies JL, Litchy WJ, O'Brien PC. Longitudinal assessment of diabetic polyneuropathy using a composite score in the Rochester Diabetic Neuropathy Study cohort. Nuerology. 1997;49(1):229-39.

[40] Shy ME, Frohman EM, Arezzo JC, Cornblath DR, Giuliani MJ, Kincaid JC, et al. Quantitatve sensory testing. Report of the Therapeutics and Technology Assessment Subcommittee of the American Academy of Neurology. Neurology. 2003;60:898-904.

[41] Arendt-Nielsen L, Yarnitsky D. Experimental and clinical applications of quantitative sensory testing applied to skin, muscles and viscera. J Pain. 2009;10(6):556-72.

[42] Freeman R, Chase KP, Risk MR. Quantitative sensory testing cannot differentiate simulated sensory loss from sensory neuropathy. Neurology. 2003;60(3):465-70.

[43] Ziegler D, Low PA, Litchy WJ, Boulton AJ, Vinik AI, Freeman R, et al. Efficacy and safety of antioxidant treatment with a-lipoic acid over 4 years in diabetic polyneuropathy: the NATHAN 1 trial. Diabetes Care. 2011;34(9):2054-60.

[44] Bird SJ, Brown MJ, Spino C, Watling S, Foyt HL. Value of repeated measures of nerve conduction and quantitative sensory testing in a diabetic neuropathy trial. Muscle Nerve. 2006;34(2):214-24.

[45] Ahmed A, Bril V, Orszag A, Paulson J, Yeung E, Ngo M, et al. Detection of Diabetic Sensorimotor Polyneuropathy by Conreal Confocal Microscopy in Type 1 Diabetes. Diabetes Care. 2012;35(4):821-8.

[46] Herrmann DN, Boger JN, Jansen C, Alessi-Fox C. In vivo confocal microscopy of Meissner corpuscles as a measure of sensory neuropathy. Neurology. 2007;69(23): 2121-7.

[47] Almodovar JL, Ferguson M, McDermott MP, Lewis RA, Shy ME, Herrmann DN. In vivo confocal microscopy of Meissner corpuscles as a novel sensory measure in CMT1A. J Peripher Nerv Syst. 2011 09/01;16(3):169-74. eng.

[48] Tracy JA, Englestad JK, Dyck PJB. Microvasculitits in diabetic lumbosacral radiculoplexus neuropathy. J Clin Neuromusc Dis. 2009;11(1):44-8. 
[49] Zochodne DW, Isaac D, Jones C. Failure of immunotherapy to prevent, arrest or reverse diabetic lubosacral plexopathy. Acta Neurol Scand. 2003;107(4):299-301.

[50] Peltier AC, Donofrio PD. Chronic inflammatory demyelinating polyradiculoneuropathy: from bench to bedside. Semin Neurol. 2012;32(3):187-95.

[51] Waaijman R, Arts MLJ, Haspels R, Busch-Westbroek TE, Nollet F, Bus SA. Pressurereduction and preservation in custom-made footware of patients with diabetes and a history of plantar ulceration. Diabet Med. 2012.

[52] Daousi C, MacFarlane IA, Woodward A, Nurmikko TJ, Bundred PE, Benbow SJ. Chronic painful peripheral neuropathy in an urban community: a controlled comparisonof people with and without diabetes. Diabet Med. 2004;21(9):976-82.

[53] Abbott CA, Malik RA, van Ross ER, Kulkarni J, Boulton AJ. Prevalence and characteristics of painful diabetic neuropathy in a large community-based diabetic population in the UK. Diabetes Care. 2011;34(10):2220-4.

[54] Sosenko JM, Boulton AJ, Kubrusly DB, JK W, Skyler JS. The vibratory perception threshold in young diabetic patients: associations with glycemia and puberty. Diabetes Care. 1985;8:605-7.

[55] Arnold R, Kwai N, Lin CS, Poynten AM, Kiernan MC, Krishnan AV. Axonal dysfunction prior to neuropathy onset in type 1 diabetes. Diabetes Metab Res Rev. 2012. Epub Sept 25, 2012.

[56] Pabbidi RM, Shuang-Quan Y, Peng S, Khardori R, Pauza ME, Premkumar LS. Influence of TRPV1 on diabetes-induced alterations in thermal pain sensitivity. Mol Pain. 2008 March 1, 2008. Epub March 1, 2008.

[57] Hong S, Wiley JW. Early painful diabetic neuropathy is associated with differential changes in the expression and function of vanilloid receptor 1. J Biol Chem. 2005;280(1):618-27.

[58] Cheng HT, Dauch JR, Hayes JM, Hong Y, Feldman EL. Nerve growth factor mediates mechanical allodynia in a mouse model of Type 2 diabetes. J Neuropathol Exp Neruol. 2009;68(11):1229-43.

[59] von Hehn CA, Baron R, Woolf CJ. Deconstructing the neuropathic pain phenotype to reveal neural mechanisms. Neuron.73(4):638-52.

[60] Galer BS, Gianas A, Jensen MP. Painful diabetic polyneuropathy: epidemiology, pain description, and quality of life. Diabetes Res Clin Pract. 2000;47(2):123-8.

[61] Watson CP, Moulin D, Watt-Watson J, Gordon A, Eisenhoffer J. Controlled-release oxycodone relieves neuropathic pain: a randomized controlled trial in painful diabetic neuropathy. Pain. 2003;105:71-8.

[62] Jarvis B, Coukell AJ. Mexiletine. A review of its therapeutic use in painful diabetiv neuropathy. Drugs. 1998;56:691-707. 
[63] Backonja M, Beydoun A, Edwards KR, Schwartz SL, Fonseca V, Hes M, et al. Gabapentin for the symptomatic treatment of painful neuropathy in patients with diabetes mellitus: a randomized controlled trial. JAMA. 1998;280(21):1831-6.

[64] Arezzo JC, Rosenstock J, LaMoreaux L, Pauer L. Efficacy and safety of pregabalin 600 $\mathrm{mg} / \mathrm{d}$ for treating painful diabetic peripheral neuropathy: A double-blind placebocontrolled trial. BMC Neurol. 2008;8. Epub Sept. 16, 2008.

[65] Goldstein DJ, Lu Y, Detke MJ, Lee TC, Iyengar S. Duloxetine vs. placebo in patients with painful diabetic neuropathy. Pain. 2005;116(1-2):109-18.

[66] Max MB, Lynch SA, Muir J, Shoaf SE, Smoller B, Dubner R. Effects of desimipramine, amitriptyline, and fluoxetine on pain in diabetic neuropathy. $\mathrm{N}$ Engl J Med. 1992;326:1250-6.

[67] Forst T, Pohlmann T, Kunt T, Goitom K, Schulz G, Lobig M, et al. The influence of local capsaicin treatment on small nerve fibre function and neurovascular control in symptomatic diabetic neuropathy. Acta Diabetol. 2002;39(1):196.

[68] Wilker SC, Rucker JC, Newman NJ, Biousse V, Tomsak RL. Pain in ischaemic ocular motor cranial nerve palsies. Br J Ophthalmol. 2009;93:1657-9.

[69] Kikta DG, Breuer AC, Wilbourn AJ. Thoracic root pain in diabetes: The spectrum of clinical and electromyographic findings. Ann Neurol. 2004;11(1):80-5.

[70] Azad N, Emanuele NV, Abraira C, Henderson WG, GColwell J, Levin SR, et al. The effects of intensive glycemic control on neuropathy in the VA cooperative study on type II diabetes mellitus. J Diabetes Complications. 1999;13(5-6):307-13.

[71] Parisi TJ, Mandrekar J, Dyck JB, Klein CJ. Meralgia paresthetica: Relation to obesity, advanced age, and diabetes mellitus. Neurology. 2011;77:1538-42.

[72] Karpitskaya Y, Novak C, Mackinnon S. Prevalence of Smoking, Obesity, Diabetes Mellitus, and Thyroid Disease in Patients with Carpel Tunnel Syndrome. Ann Plast Surg. 2002;48(3):269-73.

[73] Perkins BA, Olaleye D, Bril V. Carpal Tunnel Syndrome in Patients with Diabetic Polyneuropathy. Diabetes Care. 2002;25:565-9.

[74] Makepeace A, Davis WA, Bruce DG, Davis TME. Incidence and determinants of carpal tunnel decompression surgery in Type 2 diabetes. The Fremantle Diabetes Study. Diabetes Care. 2008;31:498-500.

[75] Duru NS, Acar H, Ayta S, Elevli M. Bilateral carpal tunnel syndrome in a child with type 1 diabetes mellitus. Neurol India. 2010;58(1):136-7.

[76] Kelkar P, Parry GJ. Mononeuritis multiplex in diabetes mellitus: evidence for underlying immune pathogenesis. J Neurol Neurosurg Psychiatry 2003;74:803-6.

[77] Albers JW, Brown MB, Sima AA, Greene DA. Frequency of median mononeuropathy in patients with mild diabetic neuropathy in the early diabetes intervention trial (ED- 
IT). Tolrestat Study For EDIT (Early Diabetes Intervention Trial). Muscle Nerve. 1996;19(2):140-6.

[78] Gupta R, Rowshan K, Chao T, Mozaffar T, Steward O. Chronic nerve compression induces local demyelination and remyelination in a rat model of carpal tunnel syndrome. Exp Neurol. 2004;187(2):500-8.

[79] Mhoon JT, Juel VC, Hobson-Webb LD. Median nerve ultrasound as a screening tool in carpal tunnel syndrome: Correlation of cross-sectional area measures with electrodiabgnostic abnormality. Muscle Nerve. Epub Oct. 5, 2012.

[80] Chaudhuri KR, Davidson AR, Morris IM. Limited joint mobility and carpal tunnel syndrome in insulin-dependent diabetes. Rheumatology. 1989;28(3):191-4.

[81] Vinik A, Mehrabyan A, Colen L, Boulton A. Focal Entrapment Neuropathies in Diabetes. Diabetes Care. 2004;27(7):1783-8.

[82] Kupersmith MJ, Heller G, Cox TA. Magnetic resonance angiography and clinical evaluation of third nerve palsies and posterior communicating artery aneurysms. J Neurosurg. 2006;105(2):228-34.

[83] Yanovitch T, Buckley E. Diagnosis and management of third nerve palsy. Curr Opin Opthalmol. 2007;18(5):373-8.

[84] Cartwright MS, Hobson-Webb LD, Boon AJ, Alter KE, Hunt CH, Flores VH, et al. Evidence-based guideline: Neuromuscular ultrasound for the diagnosis of carpal tunnel syndrome. Muscle Nerve. 2012;46(2):287-93.

[85] Hobson-Webb LD, Massey JM, Juel VC. Nerve ultrasound in diabetic polyneuropathy: Correlation with clinical characteristics and electrodiagnostic testing.Muscle Nerve. Epub Aug. 13, 2012.

[86] Riazi S, Bril V, Perkins BA, Abbas S, Chan VWS, Ngo M, et al. Can ultrasound of the tibial nerve detect diabetic peripheral neuropathy. Diabetes Care. Epub Oct. 1, 2012.

[87] Kerasnoudis A. Ultrasound and MRI in Carpal Tunnel Sydrome: The Dilemma of Simplifying the Approach to a Complex Disease or Making Complex Assessments of a Simple Problem. J Hand Surg 37(10):2200-1.

[88] Thomsen NOB, Rosen I, Dahlin LB. Neurophysiologic recovery after carpal tunnel release in diabetic patients. Clinical Neurophysiology. 2010;121(9):1569-73.

[89] Mondelli M, Padua L, Reale F, Signorini AM, Romano C. Outcome of surgical release among diabetics with carpal tunnel syndrome. Arch Phys Med Rehabil. 2004;85(1): 7-13.

[90] Wake DJ, Wright RJ, Love SC, Campbell IW. Ulnar mononeuropathy in diabetes mellitus. British J of Diabetes and Vascular Disease. 2005;5:171-2. 
[91] Kanazawa A, Haginomori S, Takamaki A, Nonaka R, Araki M, Takenaka H. Prognosis for Bell's palsy: a comparison of diabetic and nondiabetic patients. Acta Otolaryngol. 2007;127:888-91.

[92] Berlit P. Isolated and combined pareses of cranial nerves II, IV, and VI. a retrospective study of 412 patients. J Neruol Sci. 1991;103:10-5.

[93] Tankova T, Cherninkova S, Koev D. Treatment for diabetic mononeuropathy with alipoic acid. Int J Clin Pract. 2005;59(6):645-50.

[94] Podwall D, Gooch C. Diabetic neuropathy: clinical features, etiology, and therapy. Curr Neurol Neurosci Rep. 2004;4(1):55-61.

[95] Maser RE, Mitchel BD, Vinik AI, Freeman R. The association between cardiovascular autonomic neuropathy and mortality in individuals with diabetes: a meta-analysis. Diabetes Care. 2003;26:1895-901.

[96] Conway B, Miller RG, Costacou T, Fried L, Kelsey S, Evans RW, et al. Adipostiy and mortality in type 1 diabetes. Int J Obes. 2009;33(7):796-805.

[97] The Diabetes Control and Complications Trial Research Group. The effect of intensive diabetes therapy on measures of autonomic nervous system function in the Diabetes Control and Complications Trial (DCCT). Diabetologia. 1998;41:416-23.

[98] Kennedy WR, Navarro X, Sutherland DER. Neuropathy profile of diabetic patients in a pancreatic transplantation program. Neurology. 1995;45:773-80.

[99] Conway B, Aroda V, Maynard JD, Matter N, Fernandez S, Ratner RE, et al. Skin Intrinsic Fluorescence Correlates with Autonomic and Distal Symmetrical Polyneuropathy in Individuals with Type 1 Diabetes. Diabetes. 2011;34(4):1000-5.

[100] Pambianco G, Costacou T, Ellis D, Becker DJ, Klein R, Orchard TJ. The 30-Year Natural History of Type 1 Diabetes Complications: The Pittsburgh Epidemiology of Complications Study Experience. Diabetes. 2006;55:1463-9.

[101] Dejgaard A. Pathophysiology and Treatment of Diabetic Neuropathy. Diabetic Medicine. 1998;15:97-112.

[102] Pop-Busui R, Low PA, Waberski BH, Martin CL, Albers JW, Feldman EL, et al. Effects of prior intensive therapy on cardiac autonomic nervous system function in type 1 diabetes mellitus: the Diabetes Control and Complications Trial/Epidemiology of Diabetes Intreventins and Complications study (DCCT/EDIC). Circulation. 2009;119(22):2886-93.

[103] Pop-Busui R. Cardiac Autonomic Neuropathy in Diabetes: A clinical perspective. Diabetes Care. 2010;33:434-41.

[104] Spallone V, Gambardella S, Maiello MR, Barini A, Frontoni S, Menzinger G. Relationship between autonomic neuropathy, 24-h blood pressure profile, and nephropathy in normotensive IDDM patients. Diabetes Care. 1994;17(6):578-84. 
[105] Stella P, Tabak AG, Zgibor JC, Orchard TJ. Late diabetes complications and non-dipping phenomenon in patients with Type 1 diabetes. Diabetes Res Clin Pract. 2006;71(1):14-20.

[106] Karavanaki K, Kazianis G, Kakleas K, Konstantopoulos I, Karayianni C. QT interval prolongation in associateion with impaired circadian variation of blood pressure and heart rate in adolescents with Type 1 diabetes. Diabet Med. 2007;24(11):1247-53.

[107] Niakan E, Harati Y, Rolak LA, Comstock JP, Rokey R. Silent myocardial infarction and diabetic cardiovascular autonomic neuropathy. Arch Intern Med. 1986;146(11): 2229-30.

[108] May O, Arildsen H, Damsgaard EM, Mickley H. Cardiovascular autonomic neuropathy in insulin-dependent diabetes mellitus: prevalence and estimated risk of coronary heart disease in the general population. J Int Med. 2000;248:483-91.

[109] Suarez GA, Clark VM, Norell JE, Kottke TE, Callahan MJ, O'Brien PC, et al. Sudden cardiac death in diabetes mellitus: risk factors in the Rochester diabetic neuropathy study. J Neurol Neurosurg Psychiatry. 2005;76(2):240-5.

[110] Ewing DJ, Boland O, Neilson JM, Cho CG, Clark BF. Autonomic neuropathy, QT lengthening, and unexpected deaths in male diabetic patients. Diabetologia. 1991;34(3):182-5.

[111] Vinik AI, Ziegler D. Diabetic cardiovascular autonomic neuropathy. Circulation. 2007;115(3):387-97.

[112] Sfarti C, Trifan A, Hutanasu C, Cojocariu C, Singeap A, Stanciu C. Prevalence of Gastroparesis in Type 1 Diabetes Mellitus and its Relationship to Dsypeptic Symptoms. J Gastrointestin Liver Dis. 2010;19(3):279-84.

[113] De Block CEM, De Leeuw IH, Pelckmans PA, Callens D, Maday E, Van Gaal LF. Delayed Gastric Emptying and Gastric Autoimmunity in Type 1 Diabetes. Diabetes Care. 2002;25(5):912-7.

[114] Jebbink HJ, Bravenboer B, Akkermans LM, vanBerge-Henegouwen GP, Smout AJ. Relationships between dyspeptic symptoms and gastrointestinal motility in patients with type 1 (insulin-dependent) diabetes mellitus. Diabetologia. 1993;36(10):948-54.

[115] Matsumoto M, Yoshimura R, Akiho H, Higuchi N, Kobayashi K, Matsui N, et al. Gastric emptying in diabetic patients by the (13)C-octanoic acid breath test: role of insulin in gastric motility. J Gastroenterol. 2007;42(6):469-74.

[116] Schvarcz E, Palmer M, Aman J, Horowitz M, Stridsberg M, Berne C. Physiological hyperglycemia slows gastric emptying in normal subjects and patients with insulindependent diabetes mellitus. Gastroenterology. 1997;113(1):60-6. 
[117] Tesfaye S, Boulton AJ, Dyck PJ, Freeman R, Horowitz M, Kempler P, et al. Diabetic neuropathies: update on definitions, diagnostic criteria, estimation of severity, and treatments. Diabetes Care. 2010;33(10):2285-93.

[118] Freeman R. Autonomic peripheral neuropathy. Lancet. 2005;365:1259-70.

[119] Kempler P, Amarenco G, Freeman R, Frontoni S, Horowitz M, Stevens M, et al. Management strategies for gastrointestinal, erectile, bladder, and sudomotor dysfuntion in patients with diabetes. Diabetes Metab Res Rev. 2011;27:665-77.

[120] Bleustein CB, Arezzo JC, Eckholdt H, Melman A. The neuropathy of erectile dysfunction. Int J Impot Res. 2002;14(6):433-9.

[121] Hamdan FB, Al-Matubsi HY. Assessment of erectile dysfuntion in diabetic patients. Int J Androl. 2008;32(2):176-85.

[122] de Tejada IS, Goldstein I, Azadzoi K, Krane RJ, Cohen RA. Impaired Neurogenic and Endothelium-mediated Relaxation of Penile Smooth Muscle from Diabetic Men with Impotence. N Engl J Med. 1989;320(16):1025-30.

[123] Enzlin P, Mathieu C, Van Den Bruel A, Vanderschueren D, Demyttenaere K. Prevalence and Predictors of Sexual Dysfunction in Patients with Type 1 Diabetes. Diabetes Care. 2003;26:409-14.

[124] Enzlin P, Rosen R, Wiegel M, Brown J, Wessells H, Gatcomb P, et al. Sexual Dysfuntion in Women with Type 1 Diabetes: Long-term findings from the DCCT/EDIC study cohort. Diabetes Care. 2009;32:780-5.

[125] Ziegler D, Stief C. Genitourinary Complications. In: Veves A, Malik RA, editors. Diabetic Neuropathy. 2nd ed. Totowa, New Jersey: Humana Press; 2007. p. 453-72.

[126] Freeman R. Hypoglycemia and the Autonomic Nervous System. In: Veves A, Malik RA, editors. Diabetic Neuropathy: Clinical Management. Contemporary Diabetes. 2nd ed. Totowa, New Jersey: Humana Press; 2007. p. 379-88.

[127] Stephenson JM, Kempler P, Perin PC, Fuller JH. Is autonomic neuropathy a risk factor for severe hypoglycaemia? The EURODIAB IDDM Complications Study. Diabetologia. 1996;39(11):1372-6.

[128] Fanelli C, Pampanelli S, Lalli C, Del Sindaco P, Ciofetta M, Lepore M, et al. Longterm intensive therapy of IDDM patients with clinically overt autonomic neuropathy: effets on hypoglycemia awareness and counterregulation. Diabetes. 1997;46(7): 1172-81.

[129] Bottini P, Boschetti E, Pampanelli S, Ciofetta M, Del Sindaco P, Scionti L, et al. Contribution of autonomic neuropathy to reduced plasma adrenaline responses to hypoglycemia in IDDM: evidence for a non-selective defect. Diabetes. 1997;46(5):814-23.

[130] Bolli GB, Fanelli CG, Porcellati F, Pampanelli S. Diabetic Autonomic Neuropathy: Response to Hypoglycemia. In: Gries FA, Cameron NE, Low PA, Ziegler D, editors. 
Textbook of Diabetic Neuropathy. Stuttgart, Germany: Georg Thieme Verlag; 2003. p. 286-94.

[131] Ryder RE, Owens DR, Hayes TM, Ghatei MA, Bloom SR. Unawareness of hypoglycaemia and inadequate hypoglycaemic counterregulation: no causal relation with diabetic autonomic neuropathy. BMJ. 1990;301(6755):783-7.

[132] Dagogo-Jack SE, Craft S, Cryer PE. Hypoglycemia-induced autonomic failure in insulin-dependent diabetes mellitus. Recent antecedent hypoglycemia reduces autonomic responses to, symptoms of, and defense against subsequent hypoglycemia. J Clin Invest. 1993;91(3):819-28.

[133] Hepburn DA, Patrick AW, Eadington DW, Ewing DJ, Frier BM. Unawareness of hypoglycaemi in insulin-treated diabetic patients: prevalence and relationship to autonomic neuropathy. Diabet Med. 1990;7(8):711-7.

[134] Fanelli C, Pampanelli S, Epifano L, Rambotti AM, Di Vincenzo A, Modarelli F, et al. Long-term recovery from unawareness, deficient counterregulation and lack of cognitive dysfuntion during hypoglycaemia, following institution of rational, intensive thereapy in IDDM. Diabetologia. 1994;37:1265-76.

[135] Cranston I, Lomas J, Maran A, Macdonald I, Amiel SA. Restoration of hypoglycaemia awareness in patients with long-duration of insulin-dependent diabetes. Lancet. 1994;344(8918):283-7.

[136] Dagogo-Jack S, Rattarasarn C, Cryer PE. Reversal of hypoglycemia unawareness, but not defective glucose counterregulation, in IDDM. Diabetes. 1994;43:1426-34.

[137] Hoeldtke RD, Bryner KD, Horvath GG, Phares RW, Broy LF, Hobbs GR. Redistribution of sudomotor responses is an early sign of sympathetic dysfunction in type 1 diabetes. Diabetes. 2001;50(2):436-43.

[138] Maggs DC, Macdonald IA, Tattersall RB. Thermoregulatory responses to hyperinsulinaemic hypoglycaemia and euglycaemia in IDDM. Diabetologia. 1994;37(7):689-96.

[139] O'Donovan D, Samson M, Feinle C, Jones KL, Horowitz M. Diabetic Autonomic Neuropathy: Gastrointesitnal Tract. In: Gries FA, Cameron NE, Low PA, Ziegler D, editors. Textbook of Diabetic Neuropathy. New York, New York: Thieme; 2003. p. 246-62.

[140] Stief CG, Ziegler D. Diabetic Autonomic Neuropathy: Urogenital System. In: Gries FA, Cameron NE, Low PA, Ziegler D, editors. Textbook of Diabetic Neuropathy. Stuttgart, Germany: Georg Thieme Verlag; 2003. p. 262-78.

[141] Wincze JP, Albert A, Bansal S. Sexual arousal in diabetic females: physiological and self-report measures. Arch Sex Behav. 1993;22(6):587-601.

[142] Dorsher PT, McIntosh PM. Neurogenic Bladder. Adv in Urol. 2012. Epub February 8, 2012. 
[143] Low PA. Postural Hypotension and Anhydrosis. In: Veves A, Malik RA, editors. Diabetic Neuropathy: Clinical Management. 2nd ed. Totowa, New Jersey: Humana Press, Inc.; 2007. p. 413-32.

[144] Kucera P, Goldenberg Z, Kurca E. Sympathetic skin response: review of the method and its clinical use. Bratisl Lek Listy. 204;105(3):108-16.

[145] Golbidi S, Laher I. Bladder dysfunction in diabetes mellitus. Frontiers in Pharmacology. 2010 November 16, 2010;1. 